\title{
The effect of processing and meaning-based output instructions on the acquisition of English simple future tense by Iranian EFL learners
}

\author{
Beiki, Sudabeh \\ Shahid Sadoughi University of Medical Sciences, Yazd, Iran (beikisudabeh@gmail.com) \\ Omidvari, Arezoo $\bowtie$ \\ Islamic Azad University, Yasuj, Iran (Omidvaria@gmail.com)
}

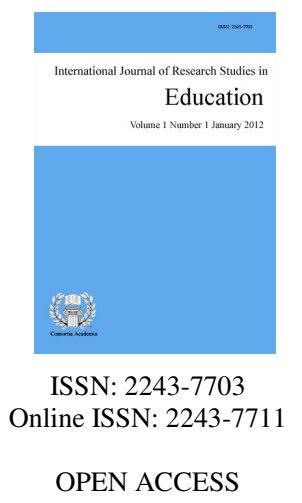

Received: 13 September 2021

Revised: 27 September 2021

Available Online: 18 October 2021

DOI: $10.5861 /$ ijrse.2021.a080

Accepted: 13 October 2021

\section{Abstract}

The aim of the present study is to explore the impacts of an input-based instruction (processing instruction, PI) and an output-based instruction (meaning-based output instruction, MOI) on the acquisition of English simple future tense by Iranian EFL learners. The participants involved in this study were beginners studying at some language Institutes in Yazd. The focus of the study was on investigating the effects of both types of instruction on learners' performance regarding their sentence-level interpretation and production skills. Participants in this study were divided in three groups: $(\mathrm{N}=60)$, Processing Instruction $(\mathrm{n}=20)$, Meaning-based Output Instruction $(n=20)$, and Control $(n=20)$. A pre-test was conducted before the treatment which followed by an immediate post-test at the interpretation and production tasks. The researcher taught the instructional treatments in the class time and acted only as a facilitator during the experiment. Two groups were trained for a total of two hours of instruction on the target feature, while the control group was deprived of the treatment. According to the data analysis, at the interpretation level, processing instruction group performed better than the meaning-based output instruction; however, the improved performance of both instructional groups was relatively equal at the production level. The control group made no improvement on the interpretation and production tasks. The results of one-way analysis of variance (ANOVA) illustrated that the learners in the experimental groups showed statistically significant gains on the acquisition of English simple future tense as compared with the control group. Due to knowledge gains and improvements by these two instructional treatments, they can provide their own pedagogical advantages to the context of second language teaching and learning.

Keywords: processing instruction, meaning-based output instruction, interpretation, production, simple future tense 


\section{The effect of processing and meaning-based output instructions on the acquisition of English simple future tense by Iranian EFL learners}

\section{Introduction}

Theorists have generally agreed that, for proper second language acquisition to take place a certain amount of comprehensible input in the target language should be received by the learners (R. Ellis, 1985; Gass, 1988 ; S. Krashen, 1982). One important issue regarding input in second language acquisition (SLA) is about how input gets processed by learners. This phenomenon is called Input Processing (IP). Van Patten (2000) defines IP as making form-meaning connections and parsing sentences (who did what to whom).

In the scope of SLA research, a fundamental role has been ascribed to output as the same as output (Swain, 1995; Izumi, 2002). Swain (1993) has developed the principles of output hypothesis based on which output may result in mental processes that both directly and indirectly affect acquisition. Research in this regard has revealed that both input and output play substantial role in the development of comprehension and production skills (Dekeyser, 1997, 2001). Meaning-based output instruction (MOI) is an instructional intervention based on the core principles of output hypothesis.

Classroom research in the effects of explicit instruction on second language acquisition has principally focused on one main issue: whether grammar instruction per se makes a positive impact in SLA. What has been neglected in this area of research relates to the question as how grammar should be taught and particularly whether there is one type of grammar instruction which is more effective than others. In fact a great deal of controversy has emerged as to which type of instructions are more beneficial. While processing instruction (PI) helps the acquisition of the forms and structures in the target language, MOI enables the access to the inter-language for accuracy and fluency in the production. Within instructed SLA, a great deal of controversy has emerged as to which types of instruction are more beneficial.

\subsection{Objectives and Significance of the Study}

The importance of input and producing some language has been highlighted by many researchers. Accordingly, the efficacies of instructional strategies which involved in receiving input and creating output are of great interest. The theoretical research on the effect of processing instruction and theoretical issues on input processing have yielded many findings and this study is sought to support the role and effects of processing instruction versus meaning-based output instruction. The findings of this study will enable researchers to see whether or not PI and MOI have beneficial effect on learners developing system with regard to their comprehension and production of the English future tense structure. The results can be regarded as significant due to the fact that, there are very few studies in Iranian EFL contexts in which PI has been compared to the other approaches.

\subsection{Research Question}

The present study was designed to answer the following question:

RQ: Is there a significant difference between the performances of Iranian EFL learners' receiving PI \& MOI on the acquisition of English simple future tense?

\subsection{Research Null Hypothesis}

The present study tried to test the following hypothesis: 
H0: There is no significant difference between the performances of Iranian EFL learners' receiving PI \& MOI on the acquisition of English simple future tense.

\section{Literature Review}

Language teaching appeared as a profession in the second half of the $20^{\text {th }}$ century. Unending changes and paradigm shifts throughout the history of this discipline have been observed. At the center of this phenomenon the concept of "methods" emerged. The method concept which in literature is perceived as a systematic set of practices based on a particular theory of language and language learning is a powerful one in the field of language teaching. Different approaches to teaching grammar have been proposed since the emergence of language teaching in foreign language situations.

Processing instruction is a pedagogical technique whose aim is to affect ways in which learners expose to input data. It is input-based as opposed to out-based and it is considered to be congruous with both general second language acquisition and communicative language teaching and its strong version task based teaching. Van Patten (1995) was the first who introduced this method of teaching and then described, discussed and researched in a number of studies (Cadierno 1995; VanPatten, 2002; Van Patten, 1993). Processing instruction is an approach which gives learners with the opportunity to process the given input through adapting some learning processes and strategies. Van Patten (1996), proposed the main purpose of this approach as "altering the processing instruction that learners take to the task of comprehension and helping them to create better form-meaning connections needed for learning than they would if left to their own devices."

Van Patten's input processing and processing instruction model is regarded as one of the innovations inspired by Krashen's input hypothesis (Krashen, 1982) because it seems to indicate it enables learners to acquire accurate grammar (Sheen, 2007). The thrust of the input hypothesis is that in order to language acquisition takes place, the learner must be provided with comprehensible input via channels of reading and hearing language structures that slightly exceed their current ability (Brown, 2000, p. 278). The role of output in the acquisition process can't be ignored in various contexts of acquisition. According to Van Patten's meaning primacy principle, learners tend to process the input for meaning before they process it for form.

Regarding the essential role of output, Swain (1995) argues that "production may force the learners to move from semantic processing to syntactic processing" (p. 249). Van Patten (2002) assigns a role to output as a tool through which learners' attention is drawn to the input and influences their accuracy and fluency. However, attributing this role to output doesn't outweigh the role input has in SLA, nor does it make input less prominent. Van Patten (2004) claims that presence or absence of a linguistic form in one's performance in the L2 in question doesn't reveal that the form has been acquired or not, and therefore, he concludes that acquisition isn't completely dependent on the output. Most of the researchers have proposed output as the most observable and accountable way in which L2 learners' linguistic knowledge is evaluated.

Four important functions that output has in the process of language learning have been highlighted by Gass, 1988; Gass \& Selinker, 2008a) receiving crucial feedback for the verification of hypotheses in the conversation; b) testing hypotheses about the structures and meanings in the target language; c) developing automaticity in IL production; and d) forcing a shift from more meaning-based processing of the second language to more syntactic mode. Benati (2001) compared the effects of a comprehension-based and a production-based type of instruction on a Romance language other than Spanish and also on a distinct differentiated form. Both of these groups had a better performance than those in the control group in the interpretation and production tests.

Sanz (2004) compared PI with a production-based approach. He eliminated the explicit information component from the input-based activities in an attempt to clarify which one of these two components would be able to explain better the effectiveness of PI. Regarding PI the explicitness was examined in terms of feedback given to the learners. Two groups of learners were randomly assigned to explicit and implicit feedback groups. Two types of Spanish clauses were tackled by the researcher: O-clitic pro V S and O-clitic pro V types of clauses. 
The procedure was the same as Van Patten \& Sanz (1995) with the distinction that the tests were in the written mode only. The findings of the study revealed that the two groups performed equally well in the acquisition of Spanish O-clitic pro V clauses, however, none of the two groups had a better performance than the other one. Therefore, it can be inferred that the type of feedback had nothing to do with the effectiveness of the PI.

Salaberry (1997) compared the relative effects of input processing and output processing on the acquisition of Spanish clitic pronouns. There were two treatment groups with activities which moved from mechanical to communicative language. The only difference meanwhile was that the latter group was required to produce some language whereas the former was only to receive input. The ability of the learners in these two treatment groups applying Spanish clitics was compared to a control group. A comprehension test, a production test, and a written narrative of a one-minute silent video used to assess knowledge incorporated the assessment. Salaberry found no significant difference between the learners who received input practice and those who received output practice in the interpretation task, however, both of the groups had some gain in this regard. The results obtained from the production and narration tasks were not affected by experiments.

Farley (2001) conducted another research in which PI was compared to meaning-based output instruction (MOI). MOI contains the use of "Structured Output" (SO) (Lee \& Van Patten, 2003). Learners need to exchange the previously unknown information in order to do these kinds of activity and they are assumed to access a particular form in order to express meaning.

To prove whether these results could be generalizable, a parallel study was conducted by Erlam (2003) in which PI as an input-based instruction was compared to an output-based instruction. The PI and the MOI were consisted of a subject pool of 70 secondary school students and the target feature was direct object pronouns in French. The assessment in this study made up of listening and reading comprehension tests and written and oral production ones. The superiority of PI on listening comprehension tests in the immediate posttest supported by the results of a split-block design testing, however, such priority was not observed in the delayed posttest. The same results were taken with regards to reading comprehension tests. On the production tests it was the PI group which improved better than the MOI group and the control group in the first posttest but again in the second posttests all three groups performed equally well on the production tests.

Mystkowska (2011) examined the effects of output and input-oriented treatment on the acquisition of English reported speeches, the participants of the study were 74 first year students of the English philology who divided into four groups: 3 treatment groups and a control one. A pretest/post-test and a delayed posttest approach were adopted to examine both short and long term effects of the three instructional treatments. The students in all experimental groups appeared to benefit from the pedagogic intervention.

Another research was conducted by Khani and Davaribina (2013) to compare the impacts of PI and MOI on the acquisition of English conditional sentences. The participants consisted of one hundred and eight intermediate level female students from six intact classes of two high schools in Sarab, Iran. Gain scores from pretest to immediate post-test and to delay post-test were considered as an indication of learning effects. The results of research indicated that PI and MOI led participants to improved performance on interpretation and production of English conditional sentences. The control group didn't show any improvement.

\section{Methodology}

The sample of the study consisted of 60 Iranian students between the ages of 11 to 14 years old. They were selected among 67 participants from private English language institutes. All of them were at basic level of proficiency in English based on the results of placement test. All participants were native speakers of Persian, that had not been exposed to any formal instruction on the target structure prior to the experiments based on the placement tests. L2 learners were split into 3 groups using a random procedure from the beginning of the study: Processing instruction group; Meaning-based output instruction (MOI); control (C) group. The difference between the PI and MOI treatment lies in the types of activities; while in the PI treatment structured input 

activities are employed, in the MOI group the instruction consisted in structured output activities. PI, MOI \& control groups contained 20 members each.

A pretest- posttest procedure using a split- block design was used to assess the effect of explicit information. All tests including pretests and immediate posttest and delayed posttests consisted of interpretation and written production tasks. No distracted task was given between the interpretation and production tasks. All Participants took a pre -test, administered before the main treatment five days before it followed by the post -test one week later. The pre-test is an interpretation task which consisted in ten sentences of which five are in the future tense. The version of post-test also consisted in ten sentences which are not highly different from the pre-test.

A week after the pretest was administered to the groups, the treatment groups PI and MOI received two complete hours of instruction whereas students of the control group were deprived of treatment. An immediate post-test which was a different version of the pre-test, was given to all participants right after the instruction. All participants took a delayed post -test as well. The experiment was designed to make the results as objective as possible within the constraints of an institute language program. Three pilot studies were conducted to collect data for this study before the final experiment.

Raw scores for each participant were computed for both the interpretation and written production tasks. Regarding the interpretation task each correct response was given a score of 1 in both the pre-test and the post-test measuring the learners' comprehension of the target feature; however, those scoring higher than 8 in the pre-test were eliminated from the study. In terms of the production task only the provision of the correct form of the verb was given a score of 1 and mistakes in other parts were not taken into account.

In order to analyze the data, Statistical Package for Social Science (SPSS) software version 25 was used. Firstly, Kolmogorov-Smirnov (K-S) test was used in order to check the normality of the data. Secondly, descriptive statistics including means and standard deviation were calculated. Finally, to examine the impacts of PI and MOI instructions on the acquisition of English simple future tense on Iranian EFL learners, a one-way analysis of variance (ANOVA) was used to work out the degree of significant difference between the performance of the learners in the PI, MOI, and Control groups on the interpretation and production tests. Also the overall performance of the three groups on two versions of the test was calculated to see which of the instructional treatments resulted in higher gains in general.

\section{Results}

In order to analyze the gathered data, the SPSS software, version 25 software was used. In order to ensure the normality of the distribution, the pretest was subjected to the use of One-Sample Kolmogorov-Smirnov (K-S) since it indicated that the sample was significantly representative of the population. The result obtained of K-S test, presented in Table 1, shows that $\mathrm{P}$ values are greater than .05 indicating that the data are normally distributed; hence, this assumption of parametric tests was met.

\section{Table 1}

Means and standard deviations for all groups on the pre-test and post-test Comprehension task

\begin{tabular}{cccc}
\hline & & Mean & \\
\hline Pre-test & PI & MOI & control \\
& 3.00 & 3.15 & 3.00 \\
& $(2.734)$ & $(2.996)$ & $(2.902)$ \\
Post-test & 14.90 & 8.10 & 2.60 \\
comprehension & $(3.824)$ & $(3.478)$ & $(2.909)$ \\
\hline
\end{tabular}

To provide a more comprehensive view of the sample randomly assigned to the PI, MOI, and control groups, one requires to obtain descriptive statistics including Mean, Standard Deviation prior to the treatment are presented. As the figure 1 shows, the mean scores and standard deviations of pretest in interpretation level for each group such as processing instruction and meaning-based output instruction were $(\mathrm{M}=3.00, \mathrm{SD}=2.734)$, 
Beiki, S., \& Omidvari, A.

$(\mathrm{M}=3.15, \mathrm{SD}=2.996)$ respectively. Furthermore, the mean score and standard deviation for the control group on pretest were $(\mathrm{M}=3.00, \mathrm{SD}=2.902)$.

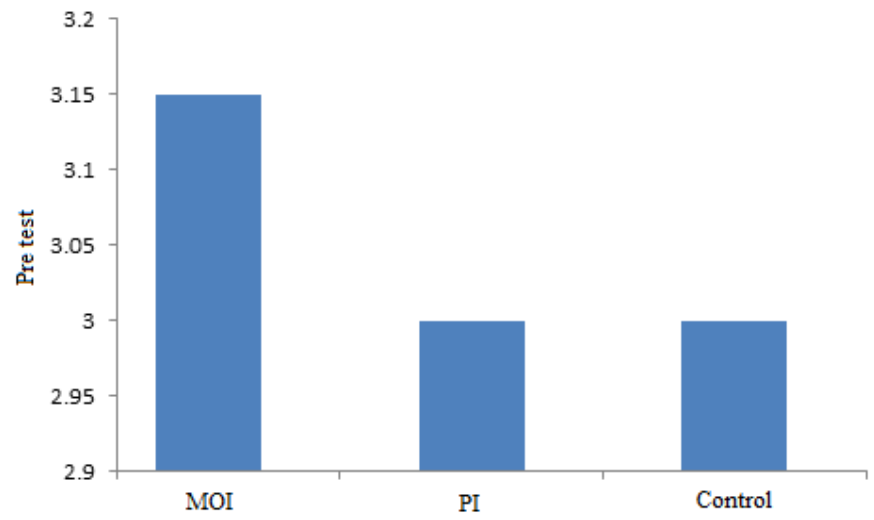

Figure 1. Mean Scores of PI, MOI, and Control Group in the Interpretation Task at Pretest Time

It can be perceived according to this figure that all the participants in the study were the same in terms of their knowledge of the target feature and any possible improvement in their performance could be considered due to the instructional treatments.

A one-way between-groups analysis of variance (ANOVA) was conducted. It was found that there wasn't a statistically significant difference between the participants in this section of the study $[F(2,57)=0.018$, $\mathrm{P}=0.982]$. Furthermore, the data indicated that the variance in scores is the same for each of the three groups, in this case, the homogeneity of the participants was observed.

Table 2

A One-Way Between-Group ANOVA of the Pre-Test

\begin{tabular}{cccccc}
\hline & Sum of squares & DF & Mean Square & F & Sig. \\
\hline Between Groups & .300 & 2 & .150 & .018 & .982 \\
Within Groups & 472.550 & 57 & 8.290 & & \\
Total & 472.850 & 59 & & & \\
\hline
\end{tabular}

Table 2 shows that all the participants in the study were similar in accordance with their knowledge of the target feature and any improvement in their performance could be considered due to the instructional treatments. The post-test section of the present study involved two versions: an interpretation post-test, the scores of which showed the learners' ability to comprehend sentences in simple future tense and a written production test constructed to estimate the degree to which the participants could produce the target feature. The purpose of the current study is to assess the overall performance of the PI and MOI groups on the interpretation and production tasks, the following statistical analyses were carried out.

\section{Table 3}

Learners' Improvement from the Pre-Test to the Overall Post-Test

\begin{tabular}{llll}
\hline & & Mean & \\
\hline Pre-Test & PI & MOI & Control \\
& 3.00 & 3.15 & 3.00 \\
\multirow{2}{*}{ Post-Test All } & 2.734 & 2.996 & 2.902 \\
& 12.23 & 9.28 & 1.93 \\
& 4.875 & 3.968 & 2.422 \\
\hline
\end{tabular}

Regarding the means and standard deviations of the participants, it can be found out that both of the experimental groups had improvements to some extent due to the instructional treatments. The Control group showed no improvement. The PI group performed better than the other two groups in general, there was a 
Processing and meaning-based output on the acquisition of English simple future tense by Iranian EFL learners significant difference between the learners on the acquisition of simple future tense $[\mathrm{F}(2,117)=74.405, \mathrm{P}<.05]$. This can be explicitly indicated in accordance with the data in table 4 .

Table 4

ANOVA Administered for the Overall Post-test

\begin{tabular}{cccccc}
\hline Post_All & Sum of Squares & Df & Mean Square & F & Sig. \\
\hline Between Groups & 2250.867 & 2 & 1125.433 & 74.405 & .000 \\
Within Groups & 1769.725 & 117 & 15.126 & & \\
Total & 4020.592 & 119 & & & \\
\hline
\end{tabular}

According to a Post-hoc comparison applying Tukey, the mean scores for the PI group $(\mathrm{M}=12.23, \mathrm{SD}=4.87)$ was significantly different from the MOI $(\mathrm{M}=9.28, \mathrm{SD}=3.96)$ and the control group $(\mathrm{M}=1.93, \mathrm{SD}=(2.42)$. The learners in the PI group had a better performance than two other groups.

Table 5

Post-hoc Comparison Test of the Post-Tests Comprehension and Production

\begin{tabular}{ccccccc}
\hline \multirow{2}{*}{$\begin{array}{c}\text { Prod/inter } \\
\text { (1) Method }\end{array}$} & (2) Method & $\begin{array}{c}\text { Mean Difference } \\
(1-2)\end{array}$ & Std. Error & Sig. & \multicolumn{2}{c}{ 95\% Confidence Interval } \\
\cline { 6 - 7 } Processing & Meaning output & $2.95000^{*}$ & .86965 & .003 & .8855 & 5.0145 \\
& Control & $10.30000^{*}$ & .86965 & .000 & 8.2355 & 12.3645 \\
Meaning output & Processing & $-2.95000^{*}$ & .86965 & .003 & -5.0145 & -.8855 \\
& Control & $7.35000^{*}$ & .86965 & .000 & 5.2855 & 9.4145 \\
& Processing & $-7.35000^{*}$ & .86965 & .000 & -9.4145 & -5.2855 \\
& Meaning output & $-10.30000^{*}$ & .86965 & .000 & -12.3645 & -8.2355 \\
\hline
\end{tabular}

\section{Discussion}

In this part the research question "Is there a significant difference between the performance of the learners receiving PI and MOI?" PI found to have some priority over the other instruction type with regards to the interpretation and production tasks. On the whole, both treatments were found to be beneficial in both interpretation and production tasks to some extent.

According to the obtained results, PI was found to have much better effect on the learners' interpretation of English simple future tense than that of the other two groups. Although the MOI group performed well in this regard, their difference in interpretation was statistically significant. Therefore, the higher gains made by the PI group can be considered due to the instruction type which was input-based. In the interpretation phase, the control group showed no evidence of improvement in performance. However, on the production task, instruction type seemed to have some main effect on both instructional groups from pre-test to post-test, but no significant difference was found between the groups producing the target feature. They performed equally well on the production tests but the control group in comparison with two other types of instruction had no improvements in comprehension and production tests. Finally, on the whole, both treatments had some effect on the learners' acquisition of the target feature.

The purpose was to examine the overall performance of the learners on both the interpretation and production assessments and the final aim dealt with the difference between the performance of experimental and control groups exposed to PI and MOI instructions. To conduct this study, 60 Iranian EFL learners studying at language institutes were involved. They were randomly assigned to two instructional groups namely, PI and MOI as well as a control group.

The procedure contained two types of treatments: explicit explanation presented in the PI treatment followed by information about the processing problem i.e. Lexical Preference principle, and a number of input-oriented 
activities. The MOI treatment received the same instruction as PI, the only difference lied in the application of output-based activities. The learners in the control group received no instructional treatment. The scores of the learners on two tasks were analyzed by SPSS. The means of the learners' scores on the interpretation and production tasks were presented using descriptive statistics. A series of one-way between-groups ANOVAs were carried out followed by post-hoc comparisons to see whether a significant difference between the learners were present or not.

Participants receiving PI and MOI instructions had equal gains on the output-based tasks at the sentence level; however, the MOI group exposed to the output-based tasks. One point worth mentioning here is that the present study conducted in Iran in which English is regarded as a foreign language. Learners are not exposed to this target language except in English language classrooms; therefore, communication can occur in this short-term period of classes. Regarding this explanation, it is not expected that the MOI group outperforms the other experimental one in terms of production. The overall results indicated the priority of PI group which cannot be considered due to their prior knowledge of the grammatical feature in question. As evidenced, the results of the pre-test showed all the learners were of the same proficiency level and they had no knowledge of the English simple future tense. Therefore, it is only the instruction type which is responsive for the obtained results in case of production.

Ultimately, the findings of the current study in accordance with the overall performance of the learners on both the interpretation and production tasks are in line with most of previous research (e.g. Benati, 2005) in which PI resulted in higher gains than the other instructions. Although, there are some studies (e.g. Keating \& Farley, 2008) in which the PI led to no noticeable improvement on each assessment.

\section{Conclusion}

The present study endeavored to investigate the relative effects of two experimental groups containing processing instruction (PI) and meaning-based output instruction (MOI) on the acquisition of English simple future tense by Iranian EFL learners. The obtained results of a pre-test and a post-test evidenced that both instructional groups led to some knowledge gains due to the treatments. It was the PI treatment which had a significant positive effect on learners' comprehension of the grammatical target form with regard to the interpretation task; even if MOI affected interpretation ability positively.

According to analysis of the scores on the production task, PI and MOI improved equally well in this regard; however, it is worth mentioning the control group showed no gains from pre-test to post-test time. Generally, it can be concluded that the instructional treatments for the learners in the present study can positively affect the acquisition of grammatical target form in different aspects.

Conflicts of Interest - There is no conflict of interests to declare.

\section{References:}

Benati, A. (2001). A comparative study of the effects of processing instruction and output-based instruction on the acquisition of the Italian future tense. Language Teaching Research, 5(2), 95-127.

Benati, A. (2005). The effects of processing instruction, traditional instruction and meaning-output instruction on the acquisition of the English past simple tense. Language Teaching Research, 9(1), 67-93.

Brown, H. D. (2000). Principles of language learning and teaching. United States of America: San Francisco State University

Cadierno, T. (1995). Formal instruction from a processing prospective: an investigation into the Spanish past tense. The Modern Language Journal, 79(2), 179-193.

DeKeyser, R. M. (1997). Beyond explicit rule learning: Automatizing second language morphosyntax. Studies in second language acquisition, 19(2), 195-221.

Dekeyser, R.M. (2001). Automaticity and automatization. In P. Robinson (Ed.), Cognition and Second Language 
Instruction (Cambridge Applied Linguistics, pp. 125-151). Cambridge: Cambridge University Press.

Ellis, R. (1985). Understanding second language acquisition (Vol. 1). Oxford: Oxford university press.

Erlam, R. (2003). Evaluating the relative effectiveness of structured-input and output-based instruction in foreign language learning. Studies in Second Language Acquisition, 25(4), 559-582.

Farley, A. P. (2001). Authentic processing instruction and the Spanish subjunctive. Hispania, 84(2), 289-299.

Gass, S. M. (1988). Integrating research areas: a framework for second language studies1. Applied linguistics, 9(2), 198-217.

Gass, S. M. (1988). Integrating Research Areas: A Framework for Second Language Studies1. Applied linguistics, 9(2), 198-217.

Gass, S. M., Behney, J., \& Plonsky, L. (2020). Second language acquisition: An introductory course. 5th Edition. New York: Routledge.

Izumi, S. (2002). Output, input enhancement, and the noticing hypothesis. Studies in Second Language Acquisition, 24(4), 541-577.

Khani, F., \& Davaribina, M. (2013). The Relative Effects of Processing Instruction and Meaning-Based Output. The Iranian EFL Journal, 9, 311.

Krashen, S. (1982). Principles and practice in second language acquisition. Los Angeles: University of Southern California.

Krashen, S. (1982). Principles and practice in second language acquisition. California: University of Southern California.

Lee, J.F., \& Van Patten, B.(2003). Making communicative language teaching happen (2nd edition). Boston: McGraw-Hill Education.

Mystkowska-Wiertelak, A. (2011). The effects of a combined output and input-oriented approach in teaching reported speech. Research in Language, 9(2), 111-126.

Salaberry, M. R. (1997). The Role of Input and Output Practice in Second Language Acquisition. Canadian Modern Language Review, 53(2), 422-451.

Sanz, C. (2003). Computer delivered implicit vs. explicit feedback in processing instruction. In VanPatten, B. (Ed.) Processing instruction (pp.241-256). Mahwah, New Jersey: Lawrence Erlbaum Associates.

Sheen, Y. (2007). The effect of focused written corrective feedback and language aptitude on ESL learners' acquisition of articles. Tesol Quarterly, 41(2), 255-283.

Swain, M. (1993). The output hypothesis: just speaking and writing aren't enough. Canadian Modern Language Review, 50(1), 158-164.

Swain, M., \& Lapkin, S. (1995). Problems in output and the cognitive processes they generate: A step towards second language learning. Applied linguistics, 16(3), 371-391.

Swain, Merrill. (1995). Three functions of output in second language learning. Principle and practice in applied linguistics: Studies in honour of HG Widdowson, 125-144.

VanPatten, B, \& Sanz, C. (1995). From input to output: Processing instruction and communicative tasks. In Eckman F. R., Mileham, J., Rutkowski Weber, R., Highland, D., \& Lee, P. W. (Eds.), Second language acquisition theory and pedagogy (pp.169-185). United Kingdom: Routledge.

VanPatten, B. (1996). Input processing and grammar instruction in second language acquisition. United States :Greenwood Publishing Group.

VanPatten, B. (1999). Processing instruction as form-meaning connections: Issues in theory and research. In J., Lee, \& A., Valdman, (Eds.),Form and meaning: Multiple perspectives (pp. 43-68). United States of America: Heinle \& Heinle.

VanPatten, B. (2002). Processing instruction: An update. Language learning, 52(4), 755-803.

VanPatten, B. (2002). Processing the Content of Input-Processing and Processing Instruction Research: A Response to DeKeyser, Salaberry, Robinson, and Harrington. Language learning, 52(4), 825-831.

VanPatten, B., \& Cadierno, T. (1993). Explicit instruction and input processing. Studies in Second Language Acquisition, 15(2), 225-243.

VanPatten, Bill. (2003). From input to output: A teacher's guide to second language acquisition. 1st Edition. New York: McGraw-Hill. 
Beiki, S., \& Omidvari, A.

Wong, W., Lightbown , P., \& Harrington, M. (2004). Input processing in second language acquisition. In B., VanPatten (Ed.) Processing instruction: theory, research, and commentary (pp. 5-31). New York: Routledge. 